\title{
Massive multiplication of genome and ribosomes in dormant cells (akinetes) of Aphanizomenon ovalisporum (Cyanobacteria)
}

\author{
Assaf Sukenik ${ }^{1}$, Ruth N Kaplan-Levy ${ }^{1}$, Jessica Mark Welch ${ }^{2}$ and Anton F Post ${ }^{2}$ \\ ${ }^{1}$ Israel Oceanographic and Limnological Research, The Yigal Allon Kinneret Limnological Laboratory, \\ Migdal, Israel and ${ }^{2}$ The Josephine Bay Paul Center for Comparative Molecular Biology and Evolution, Marine \\ Biology Laboratory, Woods Hole, MA, USA
}

\begin{abstract}
Akinetes are dormancy cells commonly found among filamentous cyanobacteria, many of which are toxic and/or nuisance, bloom-forming species. Development of akinetes from vegetative cells is a process that involves morphological and biochemical modifications. Here, we applied a single-cell approach to quantify genome and ribosome content of akinetes and vegetative cells in Aphanizomenon ovalisporum (Cyanobacteria). Vegetative cells of $\boldsymbol{A}$. ovalisporum were naturally polyploid and contained, on average, eight genome copies per cell. However, the chromosomal content of akinetes increased up to 450 copies, with an average value of 119 genome copies per akinete, 15-fold higher than that in vegetative cells. On the basis of fluorescence in situ hybridization, with a probe targeting 16S rRNA, and detection with confocal laser scanning microscopy, we conclude that ribosomes accumulated in akinetes to a higher level than that found in vegetative cells. We further present evidence that this massive accumulation of nucleic acids in akinetes is likely supported by phosphate supplied from inorganic polyphosphate bodies that were abundantly present in vegetative cells, but notably absent from akinetes. These results are interpreted in the context of cellular investments for proliferation following a long-term dormancy, as the high nucleic acid content would provide the basis for extended survival, rapid resumption of metabolic activity and cell division upon germination.
\end{abstract}

The ISME Journal (2012) 6, 670-679; doi:10.1038/ismej.2011.128; published online 6 October 2011

Subject Category: microbial ecology and functional diversity of natural habitats

Keywords: akinetes; cyanobacteria; fluorescence in situ hybridization; polyphosphate; polyploidy; laser microdissection microscopy

\section{Introduction}

Members of the order Nostocales are abundant, bloom-forming cyanobacteria. They are found in diverse aquatic environments such as fresh water lakes and reservoirs, estuaries, coastal lagoons and the open ocean. Major blooms have been reported in Australia, Northern Europe, India, New Zealand, South Africa, USA and the Baltic Sea (Carmichael et al., 1990; Codd et al., 1999; Hudnell et al., 2008), indicating a phenomenon of global dimensions. Many Nostocales species produce potent toxins that have been associated with livestock deaths, water quality deterioration and seafood contamination (Codd et al., 2005; Dittmann and Wiegand, 2006; van Apeldoorn et al., 2007). The ability to develop

Correspondence: A Sukenik, Israel Oceanographic and Limnological Research, The Yigal Allon Kinneret Limnological Laboratory, PO Box 447, Migdal 14950, Israel.

E-mail: assaf@ocean.org.il

Received 2 May 2011; revised 9 August 2011; accepted 11 August 2011; published online 6 October 2011 akinetes (spore-like cells) is a survival trait of the Nostocales that provides these toxic species with a competitive advantage over other phytoplankton. Akinetes differentiate from vegetative cells and provide a seed bank for rapid repopulation of the water column (Hori et al., 2003; Karlsson-Elfgren et al., 2004). These dormant cells survive harsh conditions in bottom sediments and dried-up shores of streams, pools and lakes. As conditions improve, akinetes germinate and the resulting vegetative cells disperse, aided by newly formed gas vacuoles (Hense and Beckmann, 2010; Kaplan-Levy et al., 2010). Morphologically, akinetes are larger and have a thicker cell wall than vegetative cells do. They contain storage compounds (i.e., cyanophycin, glycogen) and a large amount of nucleic acids. Akinetes of Anabaena cylindrica contained twice as much DNA and 10-fold more protein than vegetative cells (Simon, 1977). These high values are in part the consequence of the increased cell size of akinetes, up to ten times the volume of the vegetative cells (Fay, 1969a,b). 4'-6-Diamidino-2-phenylindole (DAPI) staining of Aphanizomenon ovalisporum 
akinetes demonstrated the accumulation of nucleic acids, their homogeneous dispersion over the entire akinete volume, and the conspicuous absence of inorganic polyphosphate (Poly-P) bodies (Sukenik et al., 2009). Here, we applied a single-cell approach to delineate the DAPI signal and demonstrate both a dramatic accumulation of genome copies and an enlarged ribosome pool in mature akinetes. These changes are interpreted in the context of cellular differentiation and modification towards a longterm dormancy, survival and rapid resumption of cell division upon germination.

\section{Materials and methods}

Culture maintenance and growth

Stock and experimental cultures of $A$. ovalisporum (strain ILC-164 from Lake Kinneret, Israel; Banker et al., 1997) were grown in liquid batch culture and transferred bi-weekly into freshly prepared BG11 medium in a 10-fold dilution (Stanier et al., 1971). Cultures were grown in $100-250 \mathrm{ml}$ flat tissueculture flasks at $24 \pm 1{ }^{\circ} \mathrm{C}$ on an orbital shaker, with continuous agitation at 100 r.p.m. and continuous illumination at $30 \mu \mathrm{mol}$ quanta $\mathrm{m}^{-2} \mathrm{~s}^{-1}$. For the induction of akinete development, trichomes from 6-day-old exponential cultures were harvested by centrifugation (3000 r.c.f.), washed with, and transferred into akinete-inducing medium (BG11 medium depleted of $\mathrm{K}^{+}$ions, as previously described; Sukenik et al., 2007). Differentiation of cells into akinetes was recognized by visual inspection under a Zeiss dissecting microscope (Carl Zeiss MicroImaging $\mathrm{GmbH}$, Jena, Germany; $\times 40$ magnification) and defined on the basis of cellular dimensions (akinetes have larger diameter) and shape as previously described (Sukenik et al., 2007, 2009).

\section{Laser microdissection microscopy}

Laser microdissection and laser pulse catapulting of vegetative cells and akinetes was performed with a PALM Combisystem that included an Axiovert $200 \mathrm{M}$ microscope interfaced with RoboMover controlled by RoboSoftware v2.0. (Carl Zeiss MicroImaging $\mathrm{GmbH}$ ). This is a fully automated, contamination-free, non-contact technology for sample capturing and collection by laser-induced transport. Using a laser pulse, a selected specimen is transported out of the object plane into a collection device such as the lid of a microfuge tube. A. ovalisporum samples were air-dried on $0.17 \mathrm{~mm}$ microscope slides $(50 \times 25 \mathrm{~mm})$, inspected and selected on the basis of pigment fluorescence, using a Zeiss fluorescence filter block (TRITC: BP535/ $50 \times$; DCXRU 585; LP590m) or bright field image (halogen-transmitted light using DIC condenser and $\times 100$ objective (Zeiss Fluar $100 \times / 1.3$ NA). Akinetes or vegetative cells were individually selected, laser excised and catapulted into the lid of a $200 \mu \mathrm{l}$ adhesive-cap tube (Carl Zeiss \#4151909191-000), or into a wet lid of a standard $200 \mu \mathrm{l}$ PCR tube. Predetermined numbers (1-5) of free akinetes were collected per tube. Similarly, filament-attached akinetes or vegetative cells from exponentially grown and akinete-induced cultures were collected. Spots of air-dried filtrate of culture suspensions were dissected, catapulted to collection tubes and used as negative controls.

\section{DNA extraction and qPCR protocols}

Quantitative PCR (qPCR) of laser microdissection and laser pulse catapulting-collected samples was performed either directly or following DNA extraction using a QIAamp DNA Mini Kit (Qiagen, Valencia, CA, USA). For this purpose, cell cohorts collected in adhesive-cap tubes were resuspended in sterile water-buffer solution, and DNA was extracted according to the manufacturer's protocol. Alternatively, laser-disrupted cells in the collecting tube lid were directly resuspended in the $1 \times$ PCR mix (SYBR Green PCR Master Mix, Applied Biosystems, Carlsbad, CA, USA) amended with the appropriate primers (Table 1). Samples were quickly centrifuged and copy numbers of the target gene (16S rRNA or ntcA) in the DNA template were quantified using the StepOnePlus Real-Time PCR System (Applied Biosystems). Real-time PCR assays were performed in a final volume of $20 \mu$ l, using the SYBR Green PCR Master Mix (Applied Biosystems). All reactions were performed with a StepOnePlus Real-Time PCR System (Applied Biosystems) using the following cycling protocol: $95^{\circ} \mathrm{C}$ for $30 \mathrm{~s}$ followed by 45 cycles at $95^{\circ} \mathrm{C}$ for $5 \mathrm{~s}$ and $60^{\circ} \mathrm{C}$ for $30 \mathrm{~s}$. At the end of each run, a DNA dissociation analysis (melting curve) was performed to ensure the absence of primer dimers, mixed-amplicon populations and/ or nonspecific products. A single direct PCR assay was performed for each sample collected by the

Table 1 A list of primer pairs and oligonucleotide probes used in this study

\begin{tabular}{|c|c|c|c|}
\hline Target & Name & Sequence & Melting temperature $\left({ }^{\circ} \mathrm{C}\right.$ \\
\hline \multirow[t]{2}{*}{$16 S$ rRNA } & $16 \sin 3$ & ATTGGGCGTAAAGGGTCTG & 60.2 \\
\hline & 16 srt3 & TTCACCGCTACACCAGGAAT & 60.4 \\
\hline \multirow[t]{2}{*}{$n t c A$} & APHntcaF & AAATGCTTGCTCCACCTGTT & 59 \\
\hline & APHntcaR & CAGGGTATACGAGGCAGGAG & 59 \\
\hline $16 S \mathrm{rRNA}$ & EUB338 & GCTGCCTCCCGTAGGAGT & 55 \\
\hline
\end{tabular}


laser dissection protocol. Triplicates of the same sample were performed only when DNA extraction was carried out before the qPCR step. Because of low DNA content, most analyses consumed the entire sample, and replication was obtained on large numbers of cells collected from the same culture. We targeted $16 S$ rRNA and the nitrogen regulatory gene ntc $A$ to determine the gene (and thus genome) copy numbers. Four copies of the $16 S$ rRNA gene were identified along the $A$. ovalisporum genome. They occurred as two identical pairs that differed by a single nucleotide (GenBank accession JF768742 to JF768745). The $n t c A$ gene was recognized as a single copy. Whereas both target genes should in theory yield identical genome copy numbers, it is clear that the higher copy number of $16 S$ rRNA enhances detection and resolution of qPCR with single-cell templates. A standard curve and a no-template control were included in each qPCR run. Standard curves were constructed using different concentrations of a plasmid that contained a fragment of the target gene (16S rRNA or ntcA) of A. ovalisporum. The concentration of the cloned plasmid stock solution was measured using a Nanodrop 2000 spectrophotometer (Thermo Scientific West Palm Beach, FL, USA) and diluted to provide a series of different plasmid DNA concentrations.

Fluorescence in situ hybridization (FISH)

Exponentially growing and akinete-induced (10 days old) cultures of $A$. ovalisporum were washed in phosphate-buffered saline (PBS: $130 \mathrm{mM} \mathrm{NaCl}$, $10 \mathrm{~mm}$ sodium phosphate buffer $\mathrm{pH}$ 8.4) and fixed in PBS containing $4 \%$ paraformaldehyde at $4{ }^{\circ} \mathrm{C}$ for $2 \mathrm{~h}$. The cells were then washed twice in PBS and collected by rapid centrifugation. The pellet was then resuspended in cold $100 \%$ methanol and incubated at $4{ }^{\circ} \mathrm{C}$ for an additional $2 \mathrm{~h}$. The fixed cells were collected by brief centrifugation, washed in lysozyme buffer (100 mM Tris-HCl pH 7.5 , and $5 \mathrm{mM} \mathrm{MgCl}_{2}$ ) and finally incubated with $1 \mathrm{mg} \mathrm{ml}^{-1}$ lysozyme (Sigma, St Louis, MO, USA, L7651) at $37^{\circ} \mathrm{C}$ for $60 \mathrm{~min}$. Lysozyme reactions were stopped by washing the sample several times in Tris-EDTA buffer (100 mM Tris-HCl pH 7.5, and $10 \mathrm{mM}$ EDTA), followed by a short wash in hybridization buffer (900 mM NaCl, $20 \mathrm{~mm}$ Tris-HCl pH 7.5, 15\% (v/v) formamide). The cells were then resuspended in $50 \mu \mathrm{l}$ of hybridization buffer. The oligonucleotide probe EUB338 (Amann et al., 1990) labeled at the $5^{\prime}$-end with Alexa 488 (Invitrogen Corp., Carlsbad, CA, USA) was added to a final concentration of $1.4 \mu \mathrm{g} \mathrm{ml}^{-1}$, and samples were incubated overnight at $46{ }^{\circ} \mathrm{C}$. For control experiments, samples were exposed to hybridization buffer that did not contain any probe. Cells were washed in washing buffer (900 mM NaCl, $20 \mathrm{~mm}$ Tris-HCl pH 7.5) and applied to microscope slides (Ultrastick, Gold Seal products Cat No 3039, Thermo Scientific). Cells retained on the slide were washed in cold de-ionized water, followed by $100 \%$ cold ethanol washes. The slides were air-dried; the sample was mounted in ProLong Gold anti-fade solution (Invitrogen), covered with a cover slip, cured overnight and kept in the dark until inspection by confocal microscopy.

\section{Hoechst staining}

Visualization of cellular DNA was facilitated by staining $A$. ovalisporum trichomes and akinetes with Hoechst 33258. Cultures (exponentially grown cultures and 10-day-old akinete-induced cultures) were fixed in $4 \%$ paraformaldehyde and then in cold methanol as described above. The fixed cells were washed in PBS, resuspended in $50 \mu \mathrm{l}$ PBS containing $10 \mu \mathrm{g} \mathrm{ml}^{-1}$ Hoechst 33258, and incubated at room temperature for $2 \mathrm{~h}$ before the staining buffer was removed by centrifugation and repeated washes. Cells were applied to microscope slides as described above and kept in the dark until inspection by confocal microscopy.

\section{Laser scanning confocal microscopy}

A Zeiss LSM 710 confocal laser-scanning microscope (Carl Zeiss MicroImaging $\mathrm{GmbH}$ ) was used for spectral analysis of $A$. ovalisporum filaments and akinetes, following their staining with fluorescent dyes. For FISH analyses, samples were excited with the $488 \mathrm{~nm}$ line of a $25 \mathrm{~mW}$ Ar laser, always using identical settings of laser power $(0.5 \%)$ and other operational parameters to confirm that maximal emission fluorescence never exceeded the saturation value of the detector, and to provide the basis for comparative data analyses between samples from different treatments and within the same frame. Emission spectra between 496 and $726 \mathrm{~nm}$ were recorded using the $\lambda$-scan function of the 'ZEN Software' (Carl Zeiss MicroImaging $\mathrm{GmbH}$ ) by acquiring an array of 24 images, each representing $9.6 \mathrm{~nm}$ of spectral width. Images of $1024 \times 1024$ pixels were collected using a Plan-Apochromat $\times 20 / 0.8$ numerical aperture objective (Carl Zeiss MicroImaging $\mathrm{GmbH}$ ). Scans were performed at a line-scan speed of $200 \mathrm{~Hz}$ (pixel dwell time $1.27 \mu \mathrm{s}$ with an average of four lines), and the confocal pinhole was opened to $173 \mu \mathrm{m}$ diameter to image an $8.8 \mu \mathrm{m}$ optical section. Samples stained with Hoechst 33258 were excited with the $405 \mathrm{~nm}$ laser line of a $30 \mathrm{~mW}$ diode $405-30$, always using the same laser power settings $(4 \%)$ and other operational parameters. Emission spectra between 429 and $716 \mathrm{~nm}$ were recorded by acquiring an array of 30 images at $9.6 \mathrm{~nm}$ intervals. Images of $512 \times 512$ pixels were collected at a line-scan speed of $77 \mathrm{~Hz}$ (pixel dwell time 25.2 microseconds with no averaging) with the confocal pinhole opened to a $118 \mu \mathrm{m}$ diameter to image a $6 \mu \mathrm{m}$ optical section. The $\lambda$-coded view of the ZEN Software supplied with the microscope was used to display a wavelength-coded color view (i.e., a color palette was automatically assigned to the individual images which are then 
displayed in a merge-type display). Mean fluorescence intensity was measured in regions of 5 pixels from a single vegetative cell or from a single akinete, using the ZEN Software supplied with the microscope. The raw spectral data were corrected against a spectrum from control samples.

\section{DAPI staining}

The presence of nucleic acids and inorganic Poly-P bodies in vegetative cells and in developing akinetes was visualized by DAPI staining, following the procedure proposed by Porter and Feig (1980). DAPI is known to form fluorescent complexes with natural double-stranded DNA, but it also binds RNA (Kapuscinski, 1995). DAPI also binds to inorganic Poly-P, resulting in a shift of the fluorescence emission to a longer wavelength with a maximum at about $525 \mathrm{~nm}$ (Siderius et al., 1996). Subsamples of Aphanizomenon cultures were fixed with $0.6 \%$ formalin final concentration. Trichomes and free akinetes were collected on Nucleopore filters $(0.2 \mu \mathrm{m}$ pore size black polycarbonate membrane cat No. 11021, Whatman Inc., Piscataway, NJ, USA) immersed in DAPI solution ( $0.6 \%$ in water) for $5 \mathrm{~min}$, and gently washed with sterile water. Samples were observed in an epi-fluorescence microscope (Axioskop Zeiss, Jena, Germany) using a high-pressure mercury source (HBO 200) interfaced with a Zeiss Filter set 02 (excitation G365, beam splitter FT 395 and emission LP 420).

\section{Neisser staining}

Confirmation of the presence of inorganic Poly-P bodies in trichomes was based on Neisser staining (Pelczar, 1957). Neisser negative cells (without Poly-P) are stained slightly brown or yellow, whereas Neisser positive cells with Poly-P bodies show dark purple-black colored globules.

\section{Results}

Accumulation of DNA in akinetes

On the basis of DAPI staining of akinetes and vegetative cells in induced cultures of $A$. ovalisporum, we previously concluded that akinetes accumulate nucleic acids (Sukenik et al., 2009). DAPI binds to DNA as well as to RNA, albeit at a lower fluorescence yield; therefore, it provides little insight in the cellular processes underlying the nucleic acid accumulation. We applied a DNA-specific dye, Hoechst 33258, to study whether DNA replication continued during akinete differentiation and maturation, in the absence of cell division. Highresolution spectral images were recorded by laser scanning confocal microscopy and presented as false-color images approximating the true colors, using the 'wavelength color-coded' setting (Figure 1). Vegetative cells showed a dominant red fluorescence signal that originated from excitation of photosynthetic pigments. Blue fluorescence derived from emission by Hoechst dye bound to DNA could hardly be visualized in vegetative cells due to high red fluorescence (Figure 1a), but was detected as relatively low $472 \mathrm{~nm}$ emission in the acquired spectral data (see Figures 2 and 3 below). Trichomes of akinete-induced cultures carried one to several akinetes during the early stages of differentiation. These young akinetes emitted blue fluorescence that was slightly stronger than that of adjacent vegetative cells (Figure 1b) and was detected as relatively higher $472 \mathrm{~nm}$ emission in the acquired spectral data (see Figure 2 below). During their maturation, akinetes continued to accumulate DNA as indicated by increasing intensity of blue fluorescence (Figure 1c). Mature akinetes contained the highest quantities of DNA, but the final amount varied considerably between individual akinetes (Figure 1d). A few akinetes lost their fluorescence properties altogether (indicated by white arrows in Figure 1d), whereas other akinetes emitted strong red fluorescence (indicated with black arrows in Figure 1d3) with minor or no blue fluorescence signal. This observation indicates that akinetes formed a heterogeneous population. The absence of fluorescence may indicate akinetes that lost their viability and their cell content was degraded during the early stages of differentiation. On the other hand, strong red fluorescence was observed in a small fraction of the akinete population. It is postulated that such akinetes had a thicker cell wall that may have formed a barrier against penetration of the Hoechst dye, that otherwise effectively penetrated the majority of akinetes. Such thick-walled akinetes also retained a high chlorophyll fluorescence signal, compared with the majority of akinetes that readily lost their chlorophyll upon fixation with 100\% methanol. Akinetes with no fluorescence or with extreme red fluorescence were omitted from further analysis.

Variations in spectral properties along Hoechststained A. ovalisporum trichomes indicated lowlevel heterogeneity among vegetative cells, whereas there were substantial differences between akinetes and their neighboring vegetative cells. Figure 2a shows a short trichome with a terminal akinete at either end. On the basis of the 472-nm fluorescence emission trace, the akinetes had a higher DNA content than the vegetative cells along that trichome, and most of the DNA was concentrated in the central part of the akinetes. The vegetative cells, however, were characterized by intense red fluorescence (655 nm emission line in Figure 2a) and low Hoechst-DNA emission intensity. Spectral properties across Hoechst-stained mature, free akinetes indicated high DNA accumulation in the central part of the cell, surrounded by photosynthetic pigment complexes (Figure 2b). The intensity of Hoechst-DNA at its emission maximum (472 nm) varied substantially among akinetes. This high 

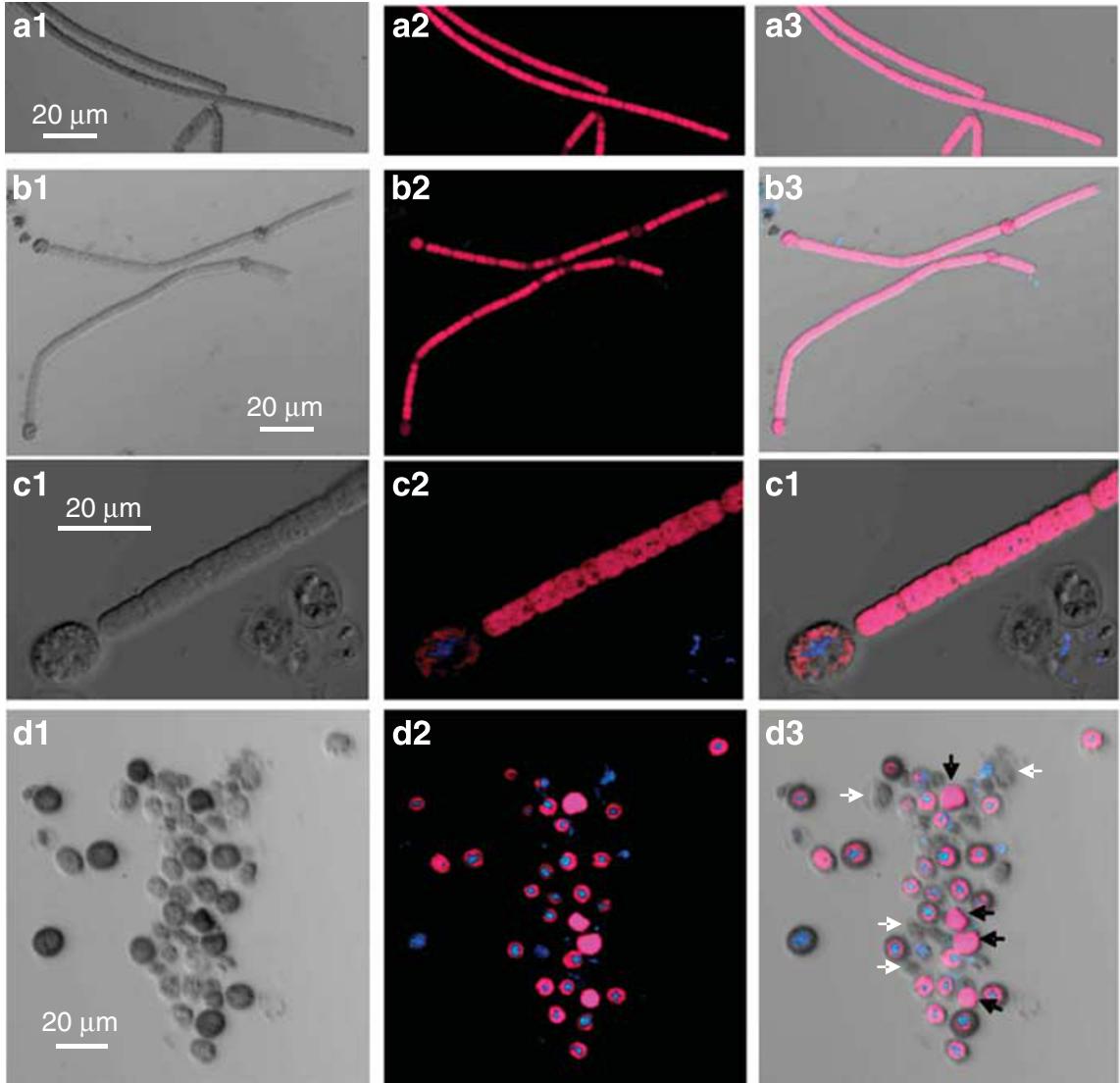

Figure 1 DNA localization during akinete differentiation and maturation in A. ovalisporum. Exponentially grown culture and akineteinduced culture stained with Hoechst 33258 and recorded by laser scanning confocal microscopy (excited with a $405 \mathrm{~nm}$ laser line). (a1-a3) Trichomes from exponentially grown culture. (b1-b3) Trichomes from an akinete-induced culture carrying akinetes at their earlier developmental stage. (c1-c3) A trichome from an akinete-induced culture carrying an akinete in its late differentiation. (d1-d3) An aggregate of free akinetes from akinete-induced culture. The images (a-d) presented for each sample are: (1) transmitted light image; (2) wavelength color-coded image and (3) a superposition of images 1 and 2. Note that some mature akinetes completely lack fluorescence signals (neither Hoechst fluorescence nor autofluorescence signals were detected-white arrows in image d3), whereas some akinetes emitted strong phycobilisomes red fluorescence (indicated with black arrows in image d3). Scale bars $=20 \mu \mathrm{m}$.

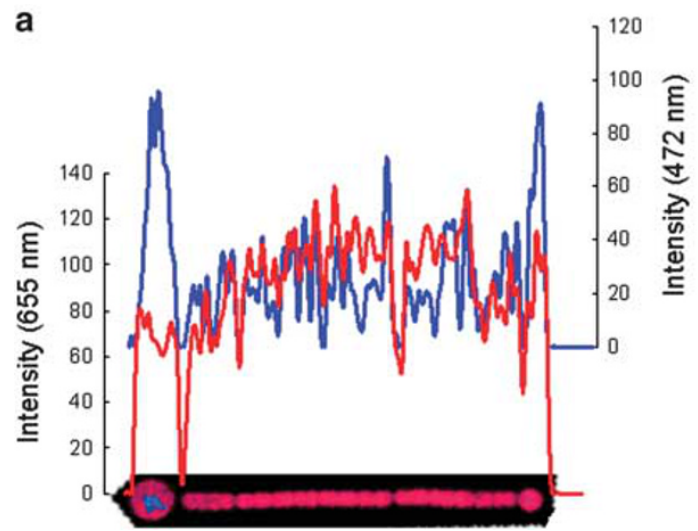

b

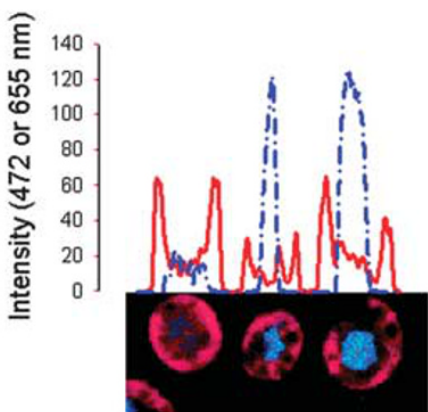

Figure 2 Lateral distribution of Hoechst-DNA $472 \mathrm{~nm}$ fluorescence (blue line) and phycobilisome autofluorescence at $655 \mathrm{~nm}$ (red line) along a short trichome with (a) terminal akinetes and (b) free mature akinetes. Wavelength color-coded image, presenting the localization of Hoechst emission (blue) and pigment autofluorescence (red), are shown together with the corresponding lateral scans of fluorescence intensity. Samples were excited with a $405 \mathrm{~nm}$ laser line.

variation is further demonstrated from the high s.d. associated with the emission spectra of Hoechststained akinetes, as compared with that of vegetative cells (Figure 3). The frequency distribution of the
$472 \mathrm{~nm}$ Hoechst-DNA emission intensities in akinetes and vegetative cells further demonstrates the high variability of DNA content in mature akinetes relative to that of vegetative cells (Figure 4). 

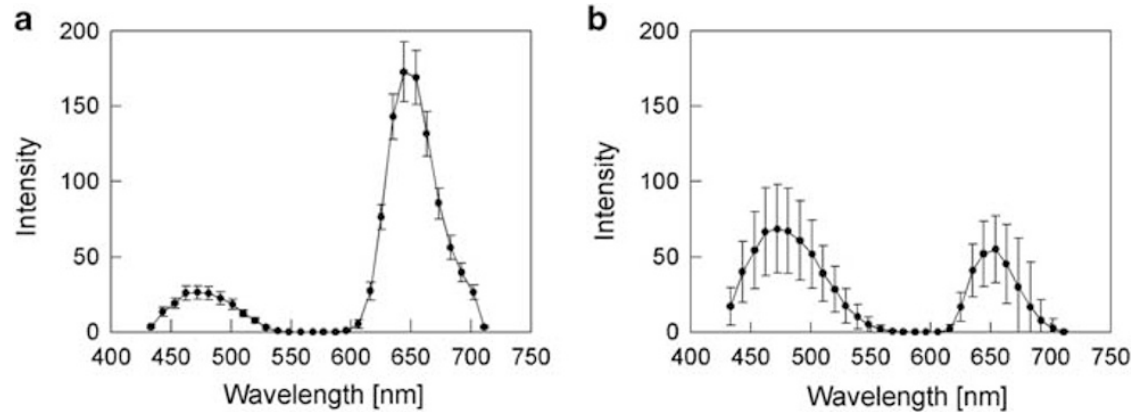

Figure 3 Averaged emission spectrum for exponentially grown vegetative cells (a) and free akinetes from akinete-induced culture (b) stained with Hoechst 33258 and recorded by a laser scanning confocal microscopy. The average spectrum and the corresponding s.d. are calculated from spectra acquired from more than 70 free akinetes or vegetative cells of exponentially grown trichomes.

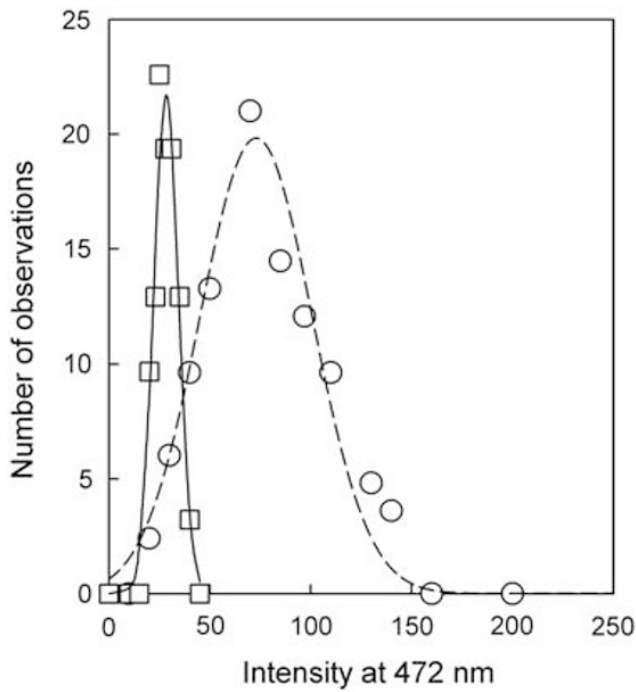

Figure 4 Frequency distribution of the Hoechst-DNA $472 \mathrm{~nm}$ emission signal in the measured population of exponentially grown vegetative cells (open squares, solid line) and free akinetes (open circles, dashed line).

Median intensity values of 70 and 28, and peak width of 34 and 6 for akinetes and vegetative cells, respectively, were estimated, suggesting higher DNA content in akinetes relative to vegetative cells.

\section{Genome replication in akinetes}

The assumption that the high DNA content in akinetes is organized in multiple identical copies of the cyanobacterial chromosome was verified by determining genome copy number in single akinetes and in cohorts of vegetative cells captured by laser microdissection microscopy. Figure 5 shows the efficiency of akinete capture and the empty site after excision and transport, indicating that the full content of the akinete was catapulted into the collection device. Single akinetes and cohorts of vegetative cells were subjected to qPCR with primer pairs designed to amplify a $170 \mathrm{bp}$ fragment of the $16 S$ rRNA gene. In the example presented in Figure 5, the $16 S$ rRNA copy number in three independent single akinete samples varied between 335 and 490, whereas in vegetative cells, it ranged between 5 and 14 per cell ( 54 and 140 copies in a sample of 10 cells). Taking into account the four copies of the rRNA operon in the A. ovalisporum genome, in this example, an akinete contained between 84 and 122 genome copies and a vegetative cell contained between 1 and 4 genome copies. This type of experiment was replicated at least 30 times for both akinetes and vegetative cells. On the basis of the accumulated data, we calculated $7.8 \pm 3.1$ genome copies per vegetative cell, whereas a single akinete contained $119 \pm 6$ genome copies, 15 times more than a vegetative cell (Table 2). The akinete population showed a broad, close to a normal distribution of genome copies that ranged between 25 and 450 per akinete (Figure 6). The number of genome copies per vegetative cell had a relatively narrow distribution (Figure 6). Results of $16 S \mathrm{rRNA}$ amplification experiments corresponded with those for ntcA (Table 2).

\section{Ribosome accumulation}

Quantification of ribosome pools in akinetes and vegetative cells was carried out by FISH, using a universal EUB338 16S rRNA probe (Amann et al., 1990) conjugated to an Alexa 488 fluorophore (Invitrogen Corp.). Examples of spectral data are presented in Figure 7. Emission spectra were recorded for individual cells, whether akinete or vegetative, always using the same image area (5 pixels) for data acquisition. Vegetative cells were evenly labeled and their emission spectra (peak at $520 \mathrm{~nm}$ ) were typical for Alexa 488. Probe hybridization to akinetes, however, varied strongly among cells (Figure 7a1) with higher average peak intensity than observed in vegetative cells. The spectral data acquired on akinetes and vegetative cells were used to determine the frequency distribution of the Alexa 488 fluorescence intensities (Figure 7b). Median intensity values of 155 and 205 were calculated for vegetative cells and akinetes, respectively.

Nucleic acids accumulate at the expense of inorganic Poly-P

DAPI staining revealed nucleic acid-enriched akinetes (blue color) and the presence of Poly-P 

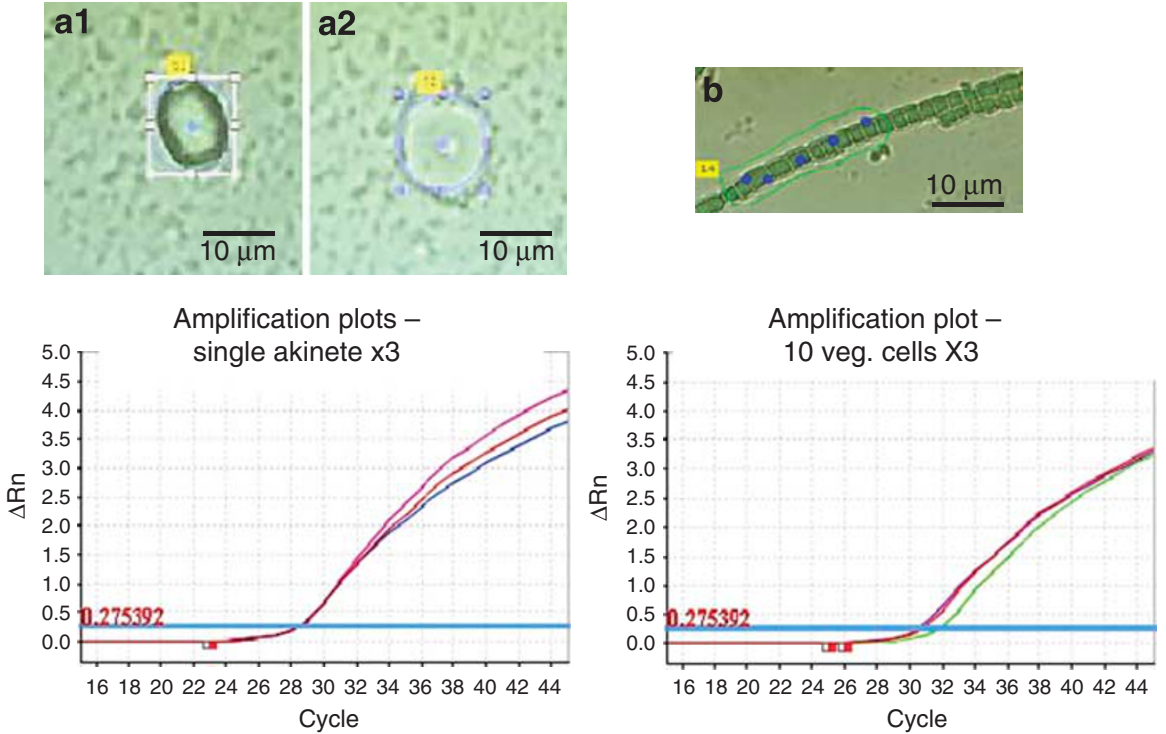

Figure 5 Amplification plots, baseline-corrected normalized fluorescence $(\Delta \mathrm{Rn})$ as a function of amplification cycle, for a $170 \mathrm{bp}$ $16 S$ rRNA fragment from a single akinete (lower left panel - each color lines represent an individual akinete) and for cohorts of 10 exponentially grown vegetative cells (lower right panel - each color lines represent a 10 cells group) of $A$. ovalisporum. A calibration curve based on a known copy number of a pBlueScript plasmid carrying a $650 \mathrm{bp}$ fragment of the $16 S \mathrm{rRNA}$ gene was run simultaneously and used to calculate gene copy number in each unknown sample (an akinetes or a cohort of 10 vegetative cells). The micrographs show a single akinete, before (a1) and after (a2) its removal by laser microdissection and laser pulse catapulting (LMPC). (b) Shows a short filament of 10 cells before LMPC.

Table 2 Genome copy number in exponentially grown vegetative cells and in free akinetes of $A$. ovalisporum

\begin{tabular}{lc}
\hline Cell type & Genome copy no. \\
\hline $\begin{array}{l}\text { Exponentially grown vegetative cells } \\
(16 S \text { rRNA) }\end{array}$ & $7.8 \pm 3.1(40)$ \\
Free akinete $(16 S$ rRNA) & $119 \pm 62(48)$ \\
Free akinete (ntcA) & $100 \pm 92(6)$ \\
\hline
\end{tabular}

Numbers are average \pm s.d. for large number of independent measurements (in parentheses). The data is based on quantitative amplification of the $16 S$ rRNA gene and verified by amplification of the $n t c A$ gene (for akinetes only).

granules/bodies (yellow-greenish color), of different sizes and shapes, in vegetative cells of Aphanizomenon (Figure 8). The absence of Poly-P bodies in mature akinetes was further confirmed by Neisser staining. Spherically shaped Poly-P bodies (dark granules of variable sizes) were abundant in vegetative cells, rarely found in developed akinetes and undetected in mature akinetes (Figure 8).

\section{Discussion}

Accumulation of nucleic acids in akinetes of Nostocales (Cyanobacteria) has been reported for numerous species and was interpreted as a requirement for dormancy and germination (Kaplan-Levy et al., 2010). We applied Hoechst 33258 as the specific DNA-binding dye to demonstrate high Hoechst-DNA fluorescence signals in akinetes

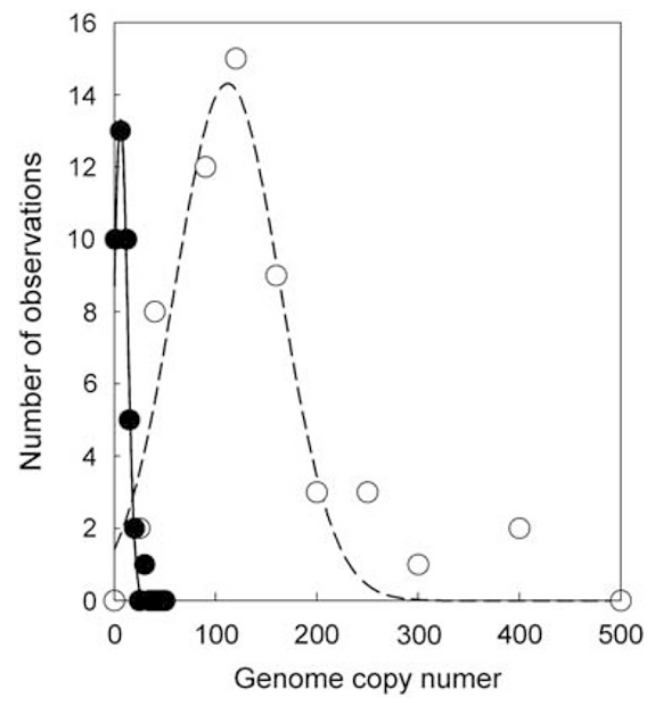

Figure 6 Frequency distribution of genome copy number per cell in vegetative cells (closed circles, solid line) and free akinetes (open circles, dashed line).

relative to vegetative cells, using a single-cell spectral analysis approach. However, the precise quantification of the cellular DNA content is rather complicated due to the intricacy of the fluorescence signal originated from a spherical body (either an akinete or a cell) and potential internal cellular quenching of the fluorescence signal. Therefore, we used a direct and quantitative, single-cell approach, to show that extensive genome replication accounts for the large nucleic acid pool in akinetes. 

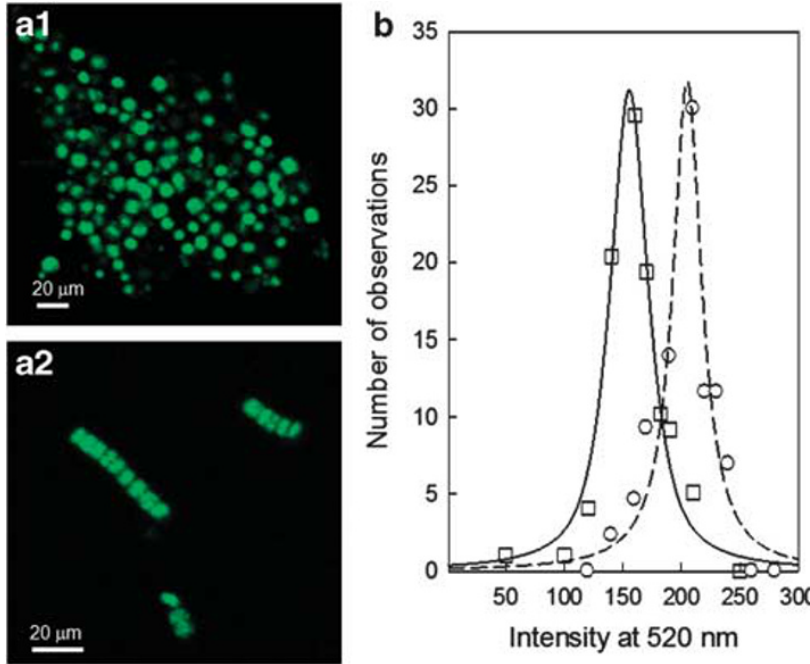

Figure 7 Quantification of cellular pools of ribosome in akinetes and vegetative cells by FISH and laser scanning confocal microscopy (samples were excited with the $488 \mathrm{~nm}$ line of a $25 \mathrm{~mW}$ Ar laser). Wavelength color-coded image (a1 and a2) are presented for akinetes and vegetative cells respectively. (b) Frequency distribution of the Alexa 488 emitted signal intensity at $520 \mathrm{~nm}$ in vegetative cells (open squares, solid line) and in free akinetes (open circles, dashed line).
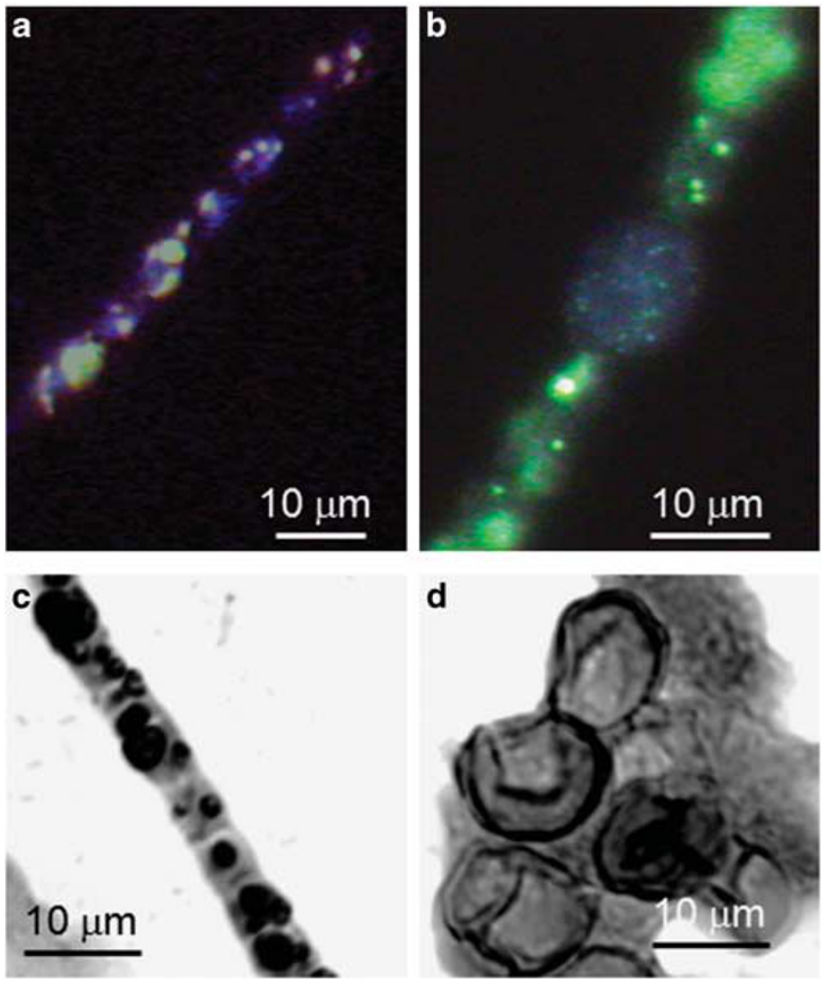

Figure 8 The presence of nucleic acids and inorganic Poly-P bodies in vegetative cells and akinetes of $A$. ovalisporum. DAPIstained samples of exponentially grown trichomes (a) and a trichome with an akinete from a 2-week-old akinete-induced culture (b), show blue fluorescence of nucleic acids and greenish fluorescence of Poly-P bodies. Neisser-stained samples of exponentially grown trichomes (c) and an aggregate of mature akinetes (d) indicate the absence of Poly-P bodies (dark color granules) in mature akinetes. Scale bars $=10 \mu \mathrm{m}$.
We have demonstrated that vegetative cells of A. ovalisporum are polyploid, with an average genome copy number of 8 , similar to that reported for Synechococcus PCC 6301, which ranged between 3 and 18 (Binder and Chisholm, 1990) or Synechocystis PCC 6803 (Labarre et al., 1989). Polyploidy was also reported for Eubacteria such as Thermus thermophilus (4-5 genome copies; Ohtani et al., 2010) and for the halophilic archaeon Halobacterium volcanii with $\sim 18$ genome copies per cell, a number which was downregulated to 10 genome copies per cell when $H$. volcanii entered stationary phase (Breuert et al., 2006). Here we report that the chromosomal content of akinetes in the cyanobacterium $A$. ovalisporum may accumulate to a maximum of 450 copies. With an average value of 119 copies per akinete, this is 15-fold higher than in vegetative cells. Such extreme levels of polyploidy are rare in prokaryotes with a single, disputed, description of polyploidy in the large bacterium Epulopiscium (Bresler et al., 1998; Robinow and Angert, 1998). PCR quantification of the Epulopiscium species type B genome suggested that this bacterium is highly polyploid with an individual cell containing $>10000$ copies of its genome (Bresler and Fishelson, 2003; Mendell et al., 2008; Liu, 2009). If cyanobacterial akinetes represent starvation or aging responses, similar to those that induce stationary phase, we would expect akinetes to show a decrease in polyploidy, such as that reported for $H$. volcanii (Breuert et al., 2006). However, considering the role of akinetes in the cyanobacterial life cycle and its resilience under harsh conditions, high polyploidy may confer a strategic advantage similar to that described for Deinococcus radiodurans (Daly and Minton, 1995) exposed to high levels of radiation or for T. thermophilus at high temperatures. Polyploidy of $A$. ovalisporum akinetes may guarantee the preservation of the integrity of the chromosome and its content over long spells of inactivity. In addition, and possibly more importantly, immediate resumption of growth upon akinete germination may be essential to rapidly establish significant populations that gain competitive advantage in the newly established environmental conditions. Processes like DNA replication require significant resources, and existing cellular reserves will help to rapidly bridge the gestation period and accelerate cell division during this stage. We also report on high variation in polyploidy within the akinete population, which is much higher than the variation between vegetative cells. The source for such a variation could stem from different metabolic status of the differentiating vegetative cell. Such variation may be predicted to affect the dormancy period and the germination efficiency.

In addition to the very substantial polyploidy of akinetes, we show that ribosomes accumulate in akinetes to a higher level than in vegetative cells. The evidence is based on FISH with a probe 
targeting the $16 S$ rRNA and its detection with confocal laser scanning microscopy. Although this method cannot be considered strictly quantitative, it provides estimates of the relative ribosome content of cells hybridized and imaged simultaneously, and using identical conditions. Assuming that the recorded FISH signal represents mainly $16 S$ rRNA associated with ribosomes, and based on the fact that fluorescence signals were always acquired from the same area ( 5 pixels), we estimate that the rRNA density (ribosome number per pixel) in akinetes is approximately $32 \%$ higher than in vegetative cells. As a first approximation and due to the larger diameter of akinetes $(12 \mu \mathrm{m}$ versus $6 \mu \mathrm{m}$ in vegetative cells) we estimate that volumetric ribosome content of akinetes exceeds that of vegetative cells by a factor of 10 (8-fold difference in volume and 1.3-fold in areal density). These estimates should be further verified by direct measurements of single cells as we did to determine polyploidy in akinetes. Nevertheless, our results clearly suggest that accumulation of ribosomes in akinetes is an inherent property of these dormant cells.

Variation in ribosome content in prokaryotes has been correlated to growth conditions and physiological status of the cells. Direct measurements reported that ribosome content in exponentially growing E. coli varied between 6800 and 72000 copies per cell (Bremer and Dennis, 1996; Vendeville et al., 2011). Furthermore, the ribosome pool changed significantly with a circa 20 -fold increase between the lag and logarithmic growth phase and a drop to less than $1 \%$ of maximum after 1 day of starvation (Nilsson et al., 1997). Several Synechococcus and Prochlorococcus strains showed relatively little change in rRNA per cell at low growth rates, linear increase at intermediate growth rates, and a plateau and/or decrease at the highest growth rates (Worden and Binder, 2003). As akinetes represent a temporarily non-dividing entity with low levels of metabolic activity, it is surprising to find such a high ribosome content. Why akinetes require high ribosome contents while their metabolic activity is substantially reduced during an extended period of dormancy remains an open question. A possible answer lies in the fact that akinete germination and development of the emerging trichome may require rapid de novo synthesis of proteins and an immediate resumption of metabolic activity.

Accumulation of ribosomes and multiplication of the genome in akinetes require the recruitment of cellular resources. Here we present evidence that phosphate is provided via the transformation of phosphate from its storage component (inorganic Poly-P bodies) in vegetative cells to enlarged pools of nucleic acids in akinetes. Inorganic Poly-P, a linear polymer of orthophosphate residues, is an essential energy source and a reservoir for metabolism and growth (Kornberg, 1995) and it has a role in regulation of fruiting body and spore development in Myxobacteria and sporulation in Bacillus (Shi et al., 2004). On the basis of cellular phosphor content of a single exponentially grown vegetative cell of $A$. ovalisporum (Hadas et al., 2002), the stored inorganic Poly-P should be sufficient for a 10 -fold increase in the number of genome copies in an akinete relative to the vegetative cell it has differentiated from. This interpretation suggests a unique function to inorganic Poly-P in Nostocales and implies an essential role of phosphate in the differentiation of akinetes, which balance between the conservation of a polymer with high-energy phosphate bonds and the yet unrevealed role of high genome copy number and ribosomes in dormant cells. One exception to this pattern is in some Nostocales species, in which phosphate limitation appeared to be the major trigger for the development of akinetes (Van Dok and Hart, 1996; Meeks et al., 2002). However, in many other cases, phosphorus was required to allow full development of akinetes (Kaplan-Levy et al., 2010).

\section{Acknowledgements}

This work was carried out at the Bay Paul Center, Marine Biology Laboratory and supported by the Gruss Lipper Foundation research award (AS). This study was part of the Joint German-Israeli-Project (FKZ 02WT0985, WR803) funded by the German Ministry of Research and Technology (BMBF) and Israel Ministry of Science and Technology (MOST). We thank Ms Katherine Hammar and Mr Blair Rossetti for their skillful technical help. Special thanks to Mr Christopher Rieken, Carl Zeiss Microimaging, Inc., for his resourceful advice and help.

\section{References}

Amann R, Binder BJ, Olson RJ, Chisholm SW, Devereux R, Stahl DA. (1990). Combination of 16S rRNA-targeted oligonucleotide probes with flow cytometry for analyzing mixed microbial populations. Appl Environ Microbiol 56: 1919-1925.

Banker R, Carmeli S, Hadas O, Teltsch B, Porat R, Sukenik A. (1997). Identification of cylindrospermopsin in Aphanizomenon ovalisporum (Cyanophyceae) isolated from Lake Kinneret, Israel. J Phycol 33: 613-616.

Binder BJ, Chisholm SW. (1990). Relationship between DNA cycle and growth rate in Synechococcus sp. strain PCC 6301. J Bacteriol 172: 2313-2319.

Bremer H, Dennis P. (1996). Modulation of cell parameters by growth rate. In: Neidhardt RCI FC, Ingraham JL, Lin ECC, Low KB, Magasanik B, Reznikoff WS et al., (eds) Escherichia coli and Salmonella: Cellular and Molecular Biology, 2nd edn. ASM press: Washington DC, pp 1553-1569.

Bresler V, Fishelson L. (2003). Polyploidy and polyteny in the gigantic eubacterium Epulopiscium fishelsoni. Marine Biol 143: 17-21.

Bresler V, Montgomery WL, Fishelson L, Pollak PE. (1998). Gigantism in a bacterium, Epulopiscium fishelsoni, correlates with complex patterns in arrangement, 
quantity, and segregation of DNA. J Bacteriol 180: 5601-5611.

Breuert S, Allers T, Spohn G, Soppa J. (2006). Regulated polyploidy in halophilic Archaea. PLOS ONE 1: e92.

Carmichael WW, Mahmood NA, Hyde EG. (1990). Natural toxins from cyanobacteria (blue-green algae). In: Hall S, Strichartz G (eds) Marine Toxins: Origin, Structure and Molecular Pharmacology. American Chemical Society: Washington DC, pp 87-106.

Codd GA, Bell SG, Kaya K, Ward CJ, Beattie KA, Metcalf JS. (1999). Cyanobacterial toxins, exposure routes and human health. Eur J Phycol 34: 405-415.

Codd GA, Morrison LF, Metcalf JS. (2005). Cyanobacterial toxins: risk management for health protection. Toxicol Appl Pharmacol 203: 264-272.

Daly MJ, Minton KW. (1995). Resistance to radiation. Science 270: 1318-1318.

Dittmann E, Wiegand C. (2006). Cyanobacterial toxins occurrence, biosynthesis and impact on human affairs. Mol Nutr Food Res 50: 7-17.

Fay P. (1969a). Cell differentiation and pigment composition in Anabaena cylindrica. Arch Mikrobiol 67: $62-70$.

Fay P. (1969b). Metabolic activities of isolated spores of Anabaena cylindrica. J Exp Bot 20: 100-109.

Hadas O, Pinkas R, Malinsky-Rushansky N, Shalev-Alon G, Delphine E, Berner T et al. (2002). Physiological variables determined under laboratory conditions may explain the bloom of Aphanizomenon ovalisporum in Lake Kinneret. Eur J Phycol 37: 259-267.

Hense I, Beckmann A. (2010). The representation of cyanobacteria life cycle processes in aquatic ecosystem models. Ecol Model 221: 2330-2338.

Hori K, Okamoto Ji, Tanji Y, Unno H. (2003). Formation, sedimentation and germination properties of Anabaena akinetes. Biochem Eng J 14: 67-73.

Hudnell HK, Ibelings BW, Havens KE. (2008). Cyanobacterial toxins: a qualitative meta-analysis of concentrations, dosage and effects in freshwater, estuarine and marine biota. Cyanobacterial Harmful Algal Blooms: State of the Science and Research Needs. Springer: New York, pp 675-732.

Kaplan-Levy RN, Hadas O, Summers ML, Rücker J, Sukenik A. (2010). Akinetes - dormant cells of cyanobacteria. In: Lubzens E, Cerda J, Clark MS (eds) Topics in Current Genetics. Springer-Verlag: Berlin, Heidelberg.

Kapuscinski J. (1995). DAPI: a DNA-specific fluorescent probe. Biotech Histochem 70: 220-233.

Karlsson-Elfgren I, Rengefors K, Gustafsson S. (2004). Factors regulating recruitment from the sediment to the water column in the bloom -forming cyanobacterium Gleotrichia echinulata. Fresh Biol 49: 265-273.

Kornberg A. (1995). Inorganic polyphosphate: toward making a forgotten polymer unforgettable. J Bacteriol 177: 491-496.

Labarre J, Chauvat F, Thuriaux P. (1989). Insertional mutagenesis by random cloning of antibiotic resistance genes into the genome of the cyanobacterium Synechocystis strain PCC 6803. J Bacteriol 171: 3449-3457.
Liu SV. (2009). How many genomes does the giant bacterium really have? Log Biol 9: 42-43.

Meeks JC, Campbell EL, Summers ML, Wong FC. (2002). Cellular differentiation in the cyanobacterium Nostoc punctiforme. Arch Microbiol 178: 395-403.

Mendell JE, Clements KD, Choat JH, Angert ER. (2008). Extreme polyploidy in a large bacterium. Proc Nat Acad Sci USA 105: 6730-6734.

Nilsson M, Bülow L, Wahlund K-G. (1997). Use of flow field-flow fractionation for the rapid quantitation of ribosome and ribosomal subunits in Escherichia coli at different protein production conditions. Biotechnol Bioeng 54: 461-467.

Ohtani N, Tomita M, Itaya M. (2010). An extreme thermophile, Thermus thermophilus, is a polyploid bacterium. J Bacteriol 192: 5499-5505.

Porter KJ, Feig YS. (1980). DAPI for identifying and counting aquatic microflora. Limnol Oceanog 25: 943-948.

Pelczar MJ. (ed) (1957). Manual for Microbiological Methods. McGraw-Hill: New York.

Robinow C, Angert ER. (1998). Nucleoids and coated vesicles of Epulopiscium spp. Arc Microbiol 170: 227-235.

Shi X, Rao NN, Kornberg A. (2004). Inorganic polyphosphate in Bacillus cereus: Motility, biofilm formation, and sporulation. Proc Natl Acad Sci USA 101: 17061-17065.

Siderius M, Musgrave A, Van Den Ende H, Koerten H, Cambier P, Van Der Meer P. (1996). Chlamydomonas eugametos (chlorophyta) stores phosphate in polyphosphate bodies together with calcium. J Phycol 32: 402-409.

Simon RD. (1977). Macromolecular composition of spores from the filamentous cyanobacterium Anabaena cylindrica. J Bacteriol 129: 1154-1155.

Stanier RY, Kunisawa R, Mandel M, Cohen-Bazire G. (1971). Purification and properties of unicellular bluegreen algae: order Chroococcales. Bacteriol Rev 35: 171-205.

Sukenik A, Beardall J, Hadas O. (2007). Photosynthetic characterization of developing and mature akinetes of Aphanizomenon ovalisporum (cyanoprokaryota). J Phycol 43: 780-788.

Sukenik A, Stojkovic S, Malinsky-Rushansky N, VinerMotzini Y, Beardall J. (2009). Fluorescence approaches reveal variations in cellular composition during formation of akinetes in the cyanobacterium Aphanizomenon ovalisporum. Eur J Phycol 44: 309-317.

van Apeldoorn ME, van Egmond HP, Speijers GJA, Bakker GJI. (2007). Toxins of cyanobacteria. Mol Nutr Food Res 51: 7-60.

Van Dok W, Hart BT. (1996). Akinete differentiation in Anabaena circinalis (Cyanophyta). J Phycol 32: 557-565.

Vendeville A, Larivière D, Fourmentin E. (2011). An inventory of the bacterial macromolecular components and their spatial organization. FEMS Microbiol Rev 35: 395-414.

Worden AZ, Binder BJ. (2003). Growth regulation of rRNA content in Prochlorococcus and Synechococcus (marine cyanobacteria) measured by whole-cell hybridization of rRNA-targeted peptide nucleic acids. J Phycol 39: 527-534. 